\title{
MAJOR RISK FACTORS FACED BY WOMEN DURING PREGNANCY IN KATHMANDU METROPOLITAN CITY
}

\author{
Sharmila Pokharel \\ Lecturer, Central Department of Health and population Education, Kirtipur, TU. \\ Corresponding author: pokhrelsharu37@tucded.edu.np
}

\begin{abstract}
Giving birth to another person's life is not a minor matter. Pregnancy can also be a risky condition that can lead to death, while some die; some survive a short-lived battle of death happens. This study aimed to identify risk factors for female pregnancy and find out the major pregnancy problems faced by pregnant women. Forty six women who teach in the Faculty of Education in Kathmandu, Nepal were taken as a sample size. A descriptive quantitative method was used where a structured questionnaire was filled with their consent. IBM SPSS 20 version was used for statistical analysis which calculated the risk estimates odd ratio and confidence interval at $95 \%$; the only normal frequency was tabulated and analyzed. This study finds that many risk factors in the pregnancy period like; health problems, lack of adequate knowledge, lifestyle exposure, and age factors. Hence women should be accompanied by their partner and family and society and support them during pregnancy time.
\end{abstract}

Keywords: major risk factors - pregnancy - knowledge - lifestyle exposure- age factors

\section{INTRODUCTION}

In most of the developing countries, WHO reported that about 5,15000 women died in a year from pregnancy-related reasons which included pregnancy and the six weeks postpartum(Pradhan et al., 2002; Stefanovic, 2020). Every sixty seconds in the world; 380 new pregnancies occur 110 complicated pregnancies, of which 40 pregnancy outcomes to abortion and a pregnant woman dies(Fathalla, 2020). Of which, 99\% of the death happens in developing countries while the remaining $1 \%$ of these deaths occur in developed countries, and the majority of these deaths 
are due to avoidable reasons(Atadag et al., 2017). Likewise, worldwide, more than 14 million adolescents become mothers each year. Of course, such births occur in all societies, but 12.8 million, or more than $90 \%$, of adolescent mothers are in developing countries. Women aged 35 and older have reported pregnancy in their late 30 s which has gradually increased over the past decade(Jolly et al., 2000; Tozzo et al., 2019). Serious pregnancy complications appear in all trimesters; since pregnancy is not a comfortable condition. Diagnosing and managing complications during pregnancy is a major challenge in developing countries like Nepal(Paudel et al., 2020).

Factors affecting pregnancy outcomes mainly include socioeconomic status, daily habits like smoking and drinking, and other health conditions and human behaviors. Different types of early pregnancy complications include miscarriage, genital trophoblastic disease, ectopic pregnancy, and hyperemesis gravid arum(Khaskheli et al., 2010). All pregnancies are not comfortable, while most pregnancies and births are very challenging, around $15 \%$ of pregnant women will face life-threatening situations and some will want a major obstetrical involvement to survive(Lampinen et al., 2009). Abortion is the most common complication during early pregnancy(Adhikari \& Wagle, 2018). It may lead to depression and anxiety in most women(Hameed et al., 2018). According to, UNICEF (1999)women need more iron than men. Iron deficiency causes many mothers in developing countries to become malnourished before and during pregnancy. One of the major causes of a review of Pregnancy in women over 35 Years of age, iron deficiency anemia is the inability to get iron-rich and iron-absorbing food, especially during the reproductive age or pregnancy (Larsson et al., 2017). Therefore, in most parts of Asia and Russia, where the prevalence of anemia is high, the WHO and UNICEF recommend iron supplements for all pregnant women (WHO, 1999).

In the Nepalese context, we can see so many risk factors that make pregnancy a menace. High-risk factors for pregnancy can be varied, such as existing health conditions, maternal age, lifestyle, and health issues that occur before or during pregnancy(Cleland \& Van Ginneken, 1988). Health in Nepal is in miserable condition as compared to the health status of developed nations of the world. This paper aims to identify the major pregnancy problems and risk factors that women face.

\section{RESEARCH METHODOLOGY}

First, the structured questionnaire was approved by consensus, and after each visit to their respective area, they filled out the questionnaire 
in front of the researcher. There are almost 46 women teachers who teach University campus, Mahendra Ratna Campus, Tahachal, and Sanothimi campus as well from the educational faculty only. The population of this study was all women who have at least a child through the census method.

After collecting the data, it was analyzed with the help of a statistical method which included risk estimates by using odd ratio and $95 \%$ confidence interval in IBM SPSS v 20(Beauclair et al., 2014). The age at which women got pregnant for the first time was initially examined as a continuous variable to explore its relationship with pregnancy-related knowledge and health problems.

\section{RESULTS}

\section{Background characteristics of the informants}

Among the respondents, the majority i.e. $56.5 \%$ of them was from the age group of 31 to 40 years, $30.4 \%$ were from more than 40 years old while the remaining $13 \%$ were below the age 30. Among them, $98 \%$ were Master's Degree holders and 2\% had a Ph.D. Degree too. 95.7\% \% of the total respondents were Hindus while the remaining were Buddhists. Among the respondents, more than two-third $71.7 \%$ earn up to 5 lakh whereas the remaining 28\% earn more than 5 lakh Nepali Rupees per year as shown in Table 1.

Table 1: Background characteristics of the respondent

\begin{tabular}{llll}
\hline \multirow{2}{*}{ Characteristics } & & Total & \\
\cline { 3 - 4 } & & $\mathbf{N}$ & $\mathbf{\%}$ \\
\hline \multirow{2}{*}{ Age group } & Upto 30 years & 6 & 13.0 \\
& 31 to 40 years & 26 & 56.5 \\
\multirow{2}{*}{ Education level } & More than 40 years & 14 & 30.4 \\
\multirow{2}{*}{ Religion } & Master Degree & 45 & 97.8 \\
& Ph. D & 1 & 2.2 \\
Income & Buddhist & 2 & 4.3 \\
& Hindu & 44 & 95.7 \\
& Up to 5 Lakh & 33 & 71.7 \\
& More than 5 Lakh & 13 & 28.3 \\
\hline
\end{tabular}

Source: Field study, 2019)

Half of the respondents married at the age of 22 to 25 years. A good majority of the respondents $(63 \%)$ expressed that they were under pressure for marriage from their parents. As shown in table 2, more than half (51\%) of respondents had only one child and $78 \%$ said the baby in their arms was their first child. 
Table 2: Background information of age of marriage and number of the child of the respondent

\begin{tabular}{|c|c|c|c|}
\hline \multirow{2}{*}{ Characteristics } & & \multicolumn{2}{|c|}{ Total } \\
\hline & & $\mathbf{N}$ & $\%$ \\
\hline \multirow[t]{4}{*}{ Age at marriage } & $16-19$ & 6 & 13 \\
\hline & $20-22$ & 12 & 26.1 \\
\hline & $22-25$ & 23 & 50 \\
\hline & 25-above & 5 & 10.9 \\
\hline \multirow{5}{*}{$\begin{array}{l}\text { Cause of marriage at } \\
\text { young }\end{array}$} & own choice or interest & 10 & 24.4 \\
\hline & parental choice / pressure & 26 & 63.4 \\
\hline & Other & 5 & 12.2 \\
\hline & Two & 18 & 40 \\
\hline & Three & 2 & 4.4 \\
\hline
\end{tabular}

Source: Field study, 2019

The majority $(40 \%)$ of women in our study said the cause of pregnancy was due to societal norms and value, whereas $27.5 \%$ of women were pregnant due to illiteracy during teenage age. More than $70 \%$ of women were not prepared when they were pregnant for the first time whereas the remaining $30 \%$ of women had planned pregnancy. Of those, $42 \%$ said that teenage pregnancy affects not only the adolescent mother but also the entire family; including the baby. More than half of the teenage pregnancy led to complications, whereas $22.5 \%$ of the total responded lost their child during pregnancy. Our findings were supported by results from rural Nepal which was conducted in 2009 (Christian et al., 2008). Their findings suggested that women aged $<19$ and $>35$ years are prone to a greater risk of pregnancy and health problems due to immature pregnancy and late delivery respectively. The majority of women i.e. $87.1 \%$ received care and support from their family and husband during pregnancy whereas remaining was neglected (Table 3). Exceptionally, the majority of women had no problem adjusting to society.

\section{DISCUSSION}

The result presented in Table 4 includes all the parameters of women who underwent pregnancy and demonstrate various significant relationships between different parameters. These results provided enough data to distinguish risk into different categories such as age and parity, 
lifestyle approaches, and social life of a woman you witness pregnancy at different ages and health conditions. Most of the respondents were under 22-25 years of age at first pregnancy. So there were a lot of people who said no to health problems at pregnancy. The age of pregnancy can also be a major factor in enhancing or reducing the risk (Pokharel, 2019).

Table 3: Background characteristics of Pregnancy-related problems

\begin{tabular}{|c|c|c|c|}
\hline Characteristics & & \multicolumn{2}{|c|}{ Total } \\
\hline \multirow{6}{*}{$\begin{array}{l}\text { Cause of teenage } \\
\text { pregnancy }\end{array}$} & Illiteracy & 11 & 27.5 \\
\hline & Religious and social norms & 16 & 40.0 \\
\hline & violence against women & 2 & 5.0 \\
\hline & relational complications & 2 & 5.0 \\
\hline & unprotected sex & 8 & 20.0 \\
\hline & Other & 1 & 2.5 \\
\hline \multirow{5}{*}{$\begin{array}{l}\text { Cause of case of } \\
\text { pregnancy }\end{array}$} & Illiteracy & 15 & 39.5 \\
\hline & violence against women & 12 & 31.6 \\
\hline & religious and social norms & 1 & 2.6 \\
\hline & unprotected sex & 4 & 10.5 \\
\hline & Other & 6 & 15.8 \\
\hline \multirow[t]{3}{*}{$\begin{array}{l}\text { Consequences of } \\
\text { teenage pregnancy }\end{array}$} & $\begin{array}{l}\text { health complication } \\
\text { death of the born child }\end{array}$ & $\begin{array}{l}22 \\
9\end{array}$ & $\begin{array}{l}55.0 \\
22.5\end{array}$ \\
\hline & Family /social conflict & 7 & 17.5 \\
\hline & Other & 2 & 5.0 \\
\hline \multicolumn{4}{|l|}{ Family support } \\
\hline Pregnancy & Neglect & 4 & 12.9 \\
\hline $\begin{array}{l}\text { Faced pregnancy } \\
\text { complications }\end{array}$ & $\begin{array}{l}\text { Yes } \\
\text { No }\end{array}$ & $\begin{array}{l}24 \\
21\end{array}$ & $\begin{array}{l}53.3 \\
46.7\end{array}$ \\
\hline \multicolumn{4}{|l|}{$\begin{array}{l}\text { Family support } \\
\text { during pregnancy }\end{array}$} \\
\hline
\end{tabular}

Source: Field study, 2019 
Table 4: Risk factors of pregnancy in women, OR: odd ratio, CI: Confidence interval

\begin{tabular}{llll}
\hline $\begin{array}{l}\text { Risk Factors faced by } \\
\text { women during pregnancy }\end{array}$ & OR & $\mathbf{9 5 \%}$ CI & \\
\hline & & Lower & Upper \\
& & & \\
Knowledge of teenage pregnancy & 6.227 & 2.207 & 17.565 \\
Health problems during pregnancy & 3.468 & 1.64 & 7.334 \\
Condition of Pregnancy & 1.642 & 0.457 & 5.894 \\
Family support during Pregnancy & 1.516 & 0.512 & 4.493 \\
Age at Marriage & 0.324 & 0.061 & 1.716 \\
First Pregnancy & 0.901 & 0.778 & 1.044 \\
\hline
\end{tabular}

Source: Field study, 2019

\section{Age and parity}

Table 4 shows that the age of pregnancy is highly significant in inducing health problems in pregnant women. Pregnancies among women who haven't reached their maturity are associated with high risks to both the pregnant mother and her fetus(DiPietro et al., 2006). Deaths during pregnancy are twice as common among adolescent women who are aged 15-19 years than women aged above the twenties(Pradhan et al., 2018). Among the respondents $85 \%$ knew about teenage pregnancy. Likewise, $40 \%$ of the respondents said that religious and social beliefs are the cause of teenage pregnancies.

Three-quarters (75\%) of respondents witnessed a teenage pregnancy case. Similarly, $55 \%$ of them linked the complications of pregnancy to the health consequences of adolescence. Half of the respondents said that the pregnancy condition was good. Of those, 63\% experienced health problems during pregnancy. Similarly, a quarter $(25 \%)$ of health problems has experienced high blood pressure, while $20 \%$ of them have experienced infections, bleeding, and pain (Table 5). Different respondents had a different perspective on pregnancy.

The majority of respondents i.e. $42 \%$ suggested that teen pregnancy is very dangerous not only for the mother but for the child too. Apart from that, $24.4 \%$ suggested that pregnancy is a natural phenomenon that is inevitable and natural while $24.4 \%$ suggested avoiding pregnancy as it has huge complications. 
Table 5: General information on pregnancy and pregnancy-related problems in the respondent

\begin{tabular}{|c|c|c|c|}
\hline \multirow{2}{*}{ Characteristics } & & \multicolumn{2}{|c|}{ Total } \\
\hline & & $\mathbf{N}$ & $\%$ \\
\hline \multirow{4}{*}{ Age at first pregnancy } & $16-19$ & 2 & 4.4 \\
\hline & $20-22$ & 10 & 22.2 \\
\hline & $22-25$ & 26 & 57.8 \\
\hline & 25-above & 7 & 15.6 \\
\hline \multirow{6}{*}{ Type of health problem } & high blood pressure & 5 & 25.0 \\
\hline & gestational diabetes & 2 & 10.0 \\
\hline & Miscarriage & 2 & 10.0 \\
\hline & bleeding and pain & 4 & 20.0 \\
\hline & $\begin{array}{l}\text { Infection, such as UTI, bacterial } \\
\text { vaginosis, etc.) }\end{array}$ & 4 & 20.0 \\
\hline & premature delivery & 3 & 15.0 \\
\hline \multirow{4}{*}{ Opinion toward pregnancy } & $\begin{array}{l}\text { there is nothing wrong with the }{ }_{1} \\
\text { pregnancy }\end{array}$ & & 24.4 \\
\hline & $\begin{array}{l}\text { pregnancy is a health risk and } \\
\text { should be avoided }\end{array}$ & & 24.4 \\
\hline & $\begin{array}{l}\text { Teen pregnancy not only } \\
\text { negatively affects the younger } 1 \\
\text { mother, but also the child }\end{array}$ & 19 & 42.2 \\
\hline & Other & 4 & 8.9 \\
\hline
\end{tabular}

Source:Field study, 2019

So, it is believed that a person's educational level is an important factor in risk reduction in the pregnancy period (Chagas de Almeida \& Aquino, 2009).

\section{Socio-economic status}

Family support during pregnancy and knowledge about teenage pregnancy plays important role in determining the health of pregnant women and newly born children(Kumar et al., 2019). A study conducted in Africa has found that any young woman enrolls in school, leaving school after becoming pregnant. There can be various reasons for this, not being allowed to leave the house, family disagreement on various issues like; no autonomy for women about their health, and the responsibility of caring 
for the child as well.Adolescent mothers play a key role in determining whether both economic and social resources are available within the family. Studies have shown that even if the mother resumes her education after the birth of the child, the education will be disrupted during pregnancy (Grant \& Hallman, 2008; Navarrete et al., 2020).

In Nepal, social and cultural taboos and embarrassments still exist towards sexual and reproductive health matters (Adhikari et al., 2020; Regmi et al., 2008). The results of odd-ratios are highly significant i.e. 95\% CI (2.2-17.5) indicating that women are at high risk during pregnancy if they are not provided with adequate knowledge and care. Meanwhile, $87 \%$ of respondents felt family support during pregnancy as shown in Table 3.

The impending birth of a child, starting with the context of family and community is a symbolizes of new life (Cavanagh \& Fomby, 2019; Sagrestano et al., 1999). Of the respondents, $26 \%$ found it difficult to integrate into society, while $37 \%$ were reluctant to socialize and communicate with others.

During pregnancy, $42 \%$ suggested that public awareness programs could reduce adolescent pregnancy and pregnancy-related problems (Table 6). Adolescent pregnancy needs to be prioritized by awareness to reduce the burden of socio-economic and health problems (Papri et al., 2016; Wado et al., 2019). The study also asked about the impact on the education of respondents, where $45 \%$ said they discontinued after pregnancy.

When asked about the cause of teenage pregnancy, many respondents said religious and social norms, while few said illiteracy. Another major cause of teenage pregnancy is unprotected sex (Table 3). Some of the effective sexuality education programs help to delay the initiation of sex, increase condom or contraceptive use, and reduce unprotected sex among youth (Kirby, 2002; Najmabadi \& Sharifi, 2019).

\section{Lifestyle exposure}

The majority of women are susceptible to sexual health-related problems during pregnancy. Health problem is also statistically positive in Nepalese women i.e. 95\% CI (1.64-7.33). The study asked about some problems; high blood pressure, gestational diabetes, Miscarriage Bleeding and pain, Infection, such as UTI, bacterial vaginosis, premature delivery, etc. 
Table 6: Impact of pregnancy on career and lifestyle of the respondents

\begin{tabular}{llll}
\hline \multirow{2}{*}{ Characteristics } & Total & $\mathbf{N}$ & $\mathbf{\%}$ \\
\hline Problem faced & & Hesitate to socialize and communicate 7 & 36.8 \\
& with others & \\
& unfit to peer groups due to being an 3 & 15.8 \\
& early mother & \\
& lack of time for relative and friends & 5 & 26.3 \\
& financial and health crisis & 2 & 10.5 \\
& Other & 2 & 10.5 \\
Pregnancy disturb & Yes & 15 & 41.7 \\
the study & No & 20 & 55.6 \\
\multirow{5}{*}{ Impact on study } & Others & 1 & 2.8 \\
& discontinue education & 9 & 45 \\
& achieved low grades in exam & 1 & 5 \\
& high absenteeism in classes & 7 & 35 \\
Opinion to & less active in the classroom activities & 3 & 15 \\
minimize & mass awareness program & 18 & 41.9 \\
& introducing teenage pregnancy since 11 & 25.6 \\
& school level & & \\
& female education program & 7 & 16.3 \\
& providing life skills to teenage girls & 6 & 14 \\
& Other & 1 & 2.3 \\
\hline
\end{tabular}

Source:Field study, 2019

High blood pressure was the common answer. During pregnancy, both low and high diastolic blood pressure is directly related to higher perinatal mortality for women of childbearing age in women (Steer et al., 2004).

According to this survey, $22.5 \%$ of women lost their firstborn baby as they were pregnant during adolescence(Table 3 ). The mortality of newborns is directly related to a lack of awareness and support from family and the presence of complicated disease (Van Otterloo \& Connelly, 2016).

\section{CONCLUSION}

Pregnancy is a very complicated condition in which various types of problems can be seen. Such problems can put the pregnancy at risk. When antenatal and maternal care is lacking, it results in the maternal mortality rate in the world. The support of husband and other family members is important to reduce the risk of pregnancy. Women married at adolescent age 
and lack of proper knowledge on pregnancy is one of the leading causes of death in under-developed countries compared to developed ones which can be prevented with simple prevention. The majority of the first born child of women didn't survive, who married during their teens and got pregnant before $<19$ years. Thus, teenage pregnancy not only affects the mother but also the family, society, and the nation as a whole. Women, who hesitated to socialize and communicate with others during pregnancy, unfit to peer groups due to being an early mother, lack of time for relative and friends, financial and health crisis were the ones with most of the risks.

\section{REFERENCES}

Adhikari, N.Uddin, S.Sapakota, K. P., \& Adhikari, S. (2020). Sexual and reproductive health needs and service utilization among adolescents in Nepal. American Journal of Public Health, 8(2): 47-53.

Adhikari, R., \& Wagle, A. (2018). Effect of intimate partner violence on pregnancy outcomes. Journal of Reproductive Health, 3(3): 17-26.

Atadag, Y.Aydın, A.Kaya, D.Oksuz, A., \& Kosker, H. D. (2017). Risk assessments, pregnancy and birth processes of pregnant women at primary health care center: A retrospective study. Journal of Surgery Medicine, 1(1): 5-8.

Beauclair, R.Petro, G., \& Myer, L. (2014). The association between timing of initiation of antenatal care and stillbirths: a retrospective cohort study of pregnant women in Cape Town, South Africa. BMC Pregnancy Childbirth, 14(1): 204.

Cavanagh, S. E., \& Fomby, P. (2019). Family instability in the lives of American children. Annual Review of Sociology, 45: 493-513.

Chagas de Almeida, M., \& Aquino, E. M. (2009). The role of education level in the intergenerational pattern of adolescent pregnancy in Brazil. International Perspectives on Sexual Reproductive Health, 139-146.

Christian, P., Katz, J., Wu, L., Kimbrough-Pradhan, E. (2008). Risk factors for pregnancy-related mortality: a prospective study in rural Nepal. Public Health, 122(2): 161-172.

Cleland, J. G., \& Van Ginneken, J. K. (1988). Maternal education and child survival in developing countries: the search for pathways of influence. Social Science Medicine, 27(12), 1357-1368. 
DiPietro, J. A.Novak, M. F.Costigan, K. A.Atella, L. D., \& Reusing, S. P. (2006). Maternal psychological distress during pregnancy in relation to child development at age two. Child Development, 77(3): 573-587.

Fathalla, M. F. (2020). Safe abortion: The public health rationale. Best Practice Research Clinical Obstetrics Gynaecology, 63: 2-12.

Grant, M. J., \& Hallman, K. K. (2008). Pregnancy related school dropout and prior school performance in KwaZulu Natal, South Africa. Studies in Family Planning, 39(4): 369-382.

Hameed, H.Hameed, A.Bashir, S.Akram, S. (2018). Study of prevalence of anaemia among pregnant women and its correlation with different risk factors drug designing. Open Access, Drug Designing, 7(1): $1-5$.

Jolly, M.Sebire, N.Harris, J.Robinson, S., \& Regan, L. (2000). The risks associated with pregnancy in women aged 35 years or older. Human Reproduction, 15(11): 2433-2437.

Khaskheli, M.Baloch, S., \& Baloch, A. S. (2010). Risk factors in early pregnancy complications. J Coll Physicians Surg Pak, 20(11): 744747.

Kirby, D. (2002). Effective approaches to reducing adolescent unprotected sex, pregnancy, and childbearing. Journal of Sex Research, 39(1): 51-57.

Kumar, G., Choudhary, T.S., Srivastava, A., Upadhyay, R.P. (2019). Utilisation, equity and determinants of full antenatal care in India: analysis from the National Family Health Survey 4. BMC Pregnancy Childbirth, 19(1): 327.

Lampinen, R.Vehviläinen-Julkunen, K., \& Kankkunen, P. (2009). A review of pregnancy in women over 35 years of age. The Open Nursing Journal, 3: 33-38.

Larsson, Å.WärnåFuru, C., \& Näsman, Y. (2017). The meaning of caring in prenatal care from Swedish women's perspectives. Scandinavian Journal of Caring Sciences, 31(4): 702-709.

Najmabadi, K. M., \& Sharifi, F. (2019). Sexual education and women empowerment in health: A review of the literature. International Journal of Women's Health Reproduction Sciences, 7(2): 150-155. 
Navarrete, L.Nieto, L., \& Lara, M. A. (2020). Intimate partner violence and perinatal depression and anxiety: Social support as moderator among Mexican women. Sexual Reproductive Healthcare, 27: 100569.

Papri, F. S.Khanam, Z.Ara, S., \& Panna, M. B. (2016). Adolescent pregnancy: risk factors, outcome and prevention. Chattagram Maa-O-Shishu Hospital Medical College Journal, 15(1): 53-56.

Paudel, S.Paudel, T., \& Sanjel, S. (2020). Utilization of antenatal care services and factors affecting antenatal care visits in Pokhara submetropolitan city. Journal of Karnali Academy of Health Sciences, 3(1): 01-12.

Pokharel, S. (2019). A review on factor influencing the involvement of male partner in antenatal care in Nepal. North American Academic Research, 2(7): 1-10.

Pradhan, E. K., West Jr, K. P., Katz, J., Christian, P. (2002). Risk of death following pregnancy in rural Nepal. Bulletin of the World Health Organization, 80: 887-891.

Regmi, P., Simkhada, P. \& Van Teijlingen, E. (2008). Sexual and reproductive health status among young people in Nepal: Opportunities and barriers for sexual health education and services utilization. Kathmandu University Medical Journal, 6(2): 1-5.

Sagrestano, L. M.Feldman, P.Rini, C. K.Woo, G., \& Dunkel-Schetter, C. (1999). Ethnicity and social support during pregnancy. American Journal of Community Psychology, 27(6): 869-898.

Steer, P. J.Little, M. P.Kold-Jensen, T.Chapple, J., \& Elliott, P. (2004). Maternal blood pressure in pregnancy, birth weight, and perinatal mortality in first births: prospective study. Bmj, 329(7478): 01-06.

Stefanovic, V. (2020). Role of obstetric ultrasound in reducing maternal and neonatal mortality in developing countries: From facts to acts. Donald School Journal of Ultrasound in Obstetrics Gynecology, 14(1): 43-49.

Tozzo, P.Fassina, A.Nespeca, P.Spigarolo, G., \& Caenazzo, L. (2019). Understanding social oocyte freezing in Italy: a scoping survey on university female students' awareness and attitudes. Life Sciences, Society Policy, 15(1): 1-14. 
UNICEF. (1999). WHO 1999 Prevention and control of iron deficiency anemia in women and children. Geneva, Switzerland, Report of the UNICEF/WHO Regional Consultation.

Van Otterloo, L. R., \& Connelly, C. D. (2016). Maternal risk during pregnancy: a concept analysis. Journal of Clinical Nursing, 25(1718): 2393-2401.

Wado, Y. D.Sully, E. A., \& Mumah, J. N. (2019). Pregnancy and early motherhood among adolescents in five East African countries: A multi-level analysis of risk and protective factors. BMC Pregnancy Childbirth, 19(1): 01-11.

WHO. (1999). Prevention and control of iron deficiency anaemia in women and children. Report of the UNICEF/WHO Regional Consultation. Geneva: WHO. 